This paper is published as:

Middleton, C. A. 2002. Who Needs a 'Killer App'? Two Perspectives on Content in Residential Broadband Networks. Journal of Research and Practice in Information Technology, 34 (2): 67-81.

This paper won the 2002 Australian Committee on Computation and Automatic Control (ANCCAC) Award for best publication in 2002 in an Australian Computer Society publication. 


\title{
Who Needs a 'Killer App'? Two Perspectives on Content in Residential Broadband Networks
}

\author{
C. A. Middleton \\ School of Information Technology Management \\ Ryerson University \\ Toronto, Canada \\ cmiddlet@ryerson.ca \\ Postal Address: 350 Victoria Street, Toronto, Ontario, Canada M5B 2K3 \\ Telephone: 00111416 979-5000 \\ Fax: 00111416 979-5249
}

\begin{abstract}
This paper describes the deployment of a residential broadband network by relating two parallel but contrasting stories. Story 1 considers network providers' search for a killer application to drive demand for broadband networks, while Story 2 suggests that consumers have already found a killer application in e-mail and basic connectivity. It appears that residential broadband networks are currently being developed with a Story 1 perspective in mind. Story 2 should be assessed in the context of its historical persistence and significance. The implications for future development of residential broadband networks are considered when both stories are accepted as plausible.
\end{abstract}

\section{ACM Categories}

Categories and Subject Descriptors: K4.3 [Computers and Society]: Organizational Impacts; K4.2 [Computers and Society]: Social Impacts; C.2.m [Computer-Communication Networks]: Miscellaneous

General Terms: Human Factors

Additional Key Words and Phrases: residential broadband networks, case study, sociotechnical systems, actor-network theory 


\title{
Who Needs a 'Killer App'? Two Perspectives on Content in Residential Broadband Networks
}

\begin{abstract}
This paper describes the deployment of a residential broadband network by relating two parallel but contrasting stories. Story 1 considers network providers' search for a killer application to drive demand for broadband networks, while Story 2 suggests that consumers have already found a killer application in e-mail and basic connectivity. It appears that residential broadband networks are currently being developed with a Story 1 perspective in mind. Story 2 should be assessed in the context of its historical persistence and significance. The implications for future development of residential broadband networks are considered when both stories are accepted as plausible.
\end{abstract}

\section{ACM Categories}

Categories and Subject Descriptors: K4.3 [Computers and Society]: Organizational Impacts; K4.2 [Computers and Society]: Social Impacts; C.2.m [Computer-Communication Networks]: Miscellaneous

General Terms: Human Factors

Additional Key Words and Phrases: residential broadband networks, case study, sociotechnical systems, actor-network theory

\section{Introduction}

Around the world, telecommunications and cable companies are providing broadband connectivity and services to consumers in their homes. Although there is no widely recognised 'killer app' that will convince apparently reluctant consumers of the value of broadband connectivity, the demand for such services is projected to grow steadily. This is despite the fact that trials of residential broadband services have consistently failed to deliver services that are appealing to consumers or that take full advantage of the potential of broadband connectivity. Instead, there is evidence that what consumers find most valuable is e-mail access and the basic connectivity among communities of users that e-mail enables. What is interesting about this finding is that it is often dismissed as trivial, or explained away by noting that the services available to users in the trials were not particularly compelling, or that once the technology improves more interesting services will be available. There seems to be an unwillingness to 
accept that connectivity, in and of itself, without additional services, may be valuable to consumers.

Using an analytical framework drawing on social construction of technology and actor-network theories, and applying it to data from Netcom (a Canadian residential broadband network trial), this paper explores resistance to the conclusion that users find value in connectivity alone. Two perspectives on residential broadband network deployments are offered. The first is consistent with the belief that broadband networks have enormous potential to offer value to users once appropriate content is developed and delivered. The second perspective shows that the value for users does not come from the technology itself, but from its enabling features that allow users to generate their own content and develop their own communities. The paper concludes by noting that these two perspectives have co-existed when other communication technologies have been introduced. It briefly explores the implications if the dominant viewpoint were to shift from the first perspective to the second, as history would suggest.

\section{Residential Broadband Networks}

In the past few years, cable and telephone companies throughout the developed world have invested heavily in upgrades to their physical plant and equipment (Ims, Myhre and Olsen, 1997; Shelanski, 1999), and they are now able to offer broadband network access to consumers in their homes. (Note that there is no consensus as to how 'broadband' is defined [Directorate for Science Technology and Industry, 2001; National Broadband Task Force, 2001; National Research Council, 2002]. The International Telecommunication Union [1997] suggests that broadband be defined by network speeds greater than primary rate ISDN, but the marketplace operationalisation of the term means that is used widely to describe any sort of high speed internet access.)

Recent OECD data on consumer adoption rates for residential broadband connectivity (Directorate for Science Technology and Industry, 2001) indicate increasing demand for residential broadband on a global basis, but there is scant 
academic literature that examines usage of broadband services from a consumer perspective. Most of what has been published about broadband focuses on issues related to the technology and technical platform required to support residential broadband connectivity (e.g. Washburn and Perrin, 1996; Hernandez-Valencia, 1997; Humphrey and Freeman, 1997; Khasnabish, 1997). There were many broadband trials in the early to mid-1990s, offering broadband services within limited geographic areas (see Maddox, 1994; Brodeur and Agarwal, 1996; Bartsch and Auer, 1997; Falkus, 1997; Rath, Wanigasekara-Mohotti, Wendorf and Verma, 1997; Zahariadis, Rosa, Pellegrinato, Lund and Stassinopoulos, 1997; Di Concetto, Pavarani, Rosa and Rossi, 1999; Dixit, 1999, for discussion of these trials). Although broadband services have been available on a commercial basis for some time now, there is as yet very little research published on the usage of such services. (The Journal of Information Technology is planning a special issue on the topic of "Broadband Internet and Electronic Commerce", to appear in 2003.)

The lack of academic commentary on user aspects of broadband trials is due in part to their proprietary nature. Trials were often funded by corporate sponsors (e.g. Time-Warner's Full Service Network trial in Orlando, USA) who wanted to keep their findings about user behaviours to themselves. However, the limited analysis that is available on the consumer aspects of residential broadband does indicate that the services offered did not fully exploit the technological capabilities of the technologies consumers were using, and that there did not seem to be a single killer application that would drive consumer demand for residential broadband networks (Snoddy, 1995; Zahariadis et al., 1997; Di Concetto et al., 1999). (The term killer application, or killer app, is used widely to signify a product or service that will drive demand for, or increase sales of, a related product or service. Searches for compelling applications that legitimise or justify the adoption of particular technologies have been recognised in the computer industry for many years [see Moore, 1994; Bragitikos, 1996 on this point].) As Akimaru, Finley and Niu (1997) note, "The need for broadband integrated services 
simply did not seem to exist, and the pilot studies of the day showed that customers were not willing to pay the extra price for new services." (p. 84). This perspective is echoed by the business press, which branded the broadband trials a failure (e.g. Mason, 1997).

\section{There is No Killer App - Or is There?}

Research at the Netcom residential broadband network trial reached similar conclusions, in that there didn't seem to be a single broadband application that was widely used by trial participants (Middleton, 1999). It should be noted however that the Netcom trial did not set out to find a killer application for broadband networks. As the trial director said, "we held the heretical notion that instead of designing the content from the perspective of solid business cases, we should present users with a great variety of applications that might be of interest to them, including community services, education and information".

Not finding a killer app for broadband in a trial that didn't set out to develop one isn't a result worth mentioning. But there is still a story worth pursuing here. It turned out that there was a popular, widely used application in the Netcom trial, but it was one that didn't require broadband network capacity. That application was e-mail, and in particular, the listserv that was set up for the exchange of information among the wired homes in the Netcom community. Discovering the popularity and success of e-mail was an interesting result for the trial researchers, as it demonstrated the value of allowing users to determine how network connectivity could suit their own needs. But some consortium partners (the trial was developed by a broad based consortium of public and private sector partner organisations) did not share the view that this was an important finding. From their perspective, the fact that e-mail was the most widely used application meant that the trial had been a failure. Many consortium partners felt that had the trial been able to deliver all the services that were planned, the findings would have been different. Audiences beyond the trial also reacted with scepticism to the suggestion that these findings were of interest, dismissing the conclusions as trivial, or 
countering with hypotheses suggesting that a) e-mail was the only viable service offered to users (thus the conclusion was obvious); b) the findings would be different if there had been 'real' broadband content like video on demand, or c) as the technology improved and users became more sophisticated things would change.

What is of interest in this paper is the strong resistance to the conclusion that email and the connectivity it enabled was important and valuable to users in the Netcom trial. It is in investigating the reluctance to accept this conclusion that some underlying assumptions inherent in the development of residential broadband networks and services can be revealed. Understanding why this finding was uncomfortable for some participants in the trial helps elucidate two strikingly different perspectives on the deployment of broadband networks and services. These perspectives are explored below.

\section{A Theoretical Framework}

The interpretive method used here draws from two related bodies of theory, namely the social construction of technology (SCOT) (e.g. Bijker, Hughes and Pinch, 1987) and actor-network theory (ANT) (see Law, 1991). A social constructionist perspective can account for "both success and failure of technology within the same theoretical framework" (Lea, O'Shea and Fung, 1995, p. 464). ANT is harder to define. Walsham (1997) observes that "actor-network theory is not a stable and unified body of knowledge which can be drawn on by researchers, since its developers frequently revise or extend elements of the theory" ( $p$ 468). Indeed, one of the founders of the theory confirms Walsham's observation, stating "there are four things that do not work with actor-network theory; the word actor, the word network, the word theory and the hyphen!" (Latour, 1999, p. 15). This makes it difficult for a researcher to know exactly how to use ANT as an interpretive tool, or to determine whether its constructs are being appropriated faithfully. However, the usage of ANT in the information systems (e.g. Woolgar, 1991; Boland and Schultze, 1996; Monteiro and Hanseth, 1996; Vigden and McMaster, 1996; Somerville, 1997; Walsham, 1997; Tatnall and Gilding, 1999) and 
organisational (Lea et al., 1995) literatures show its value in "provid[ing] a very good way of telling stories about 'what happens out there' that defamiliarizes what we may otherwise take for granted" (Calás and Smircich, 1999, p. 663).

The approach here, (following Lea et al., 1995) is to draw on SCOT and ANT constructs of multiple narratives (Boland \& Schultze, 1996), interpretive flexibility and closure/irreversibility to explore the nature of residential broadband networks and their deployment as a socio-technical system. Two narratives, well supported by data, but offering quite different perspectives on residential broadband networks, set the stage for further analysis. The narratives show the interpretive flexibility inherent in residential broadband networks, meaning that "the technology is open to more than one interpretation; it can mean different things to different individuals or different groups" (Lea et al., 1995, p. 463). Over time however, the interpretation of most technologies and the socio-technical systems they are embedded in becomes stable, abandoning interpretive flexibility and reaching a state of closure or irreversibility (Callon, 1991). As such, it is important to understand the relationships among actors in the socio-technical system (known as the actor-network), and to consider how they might be affected as the relationship becomes irreversible. In this case, the actor-network includes the broadband network itself, the content and services delivered over it, and the users. These actors are participants in a negotiation that may result in closure around a particular interpretation of the technology.

In the following section, the two interpretations of the Netcom residential broadband network trial are presented. The actor-networks underlying each interpretation are described, showing the competing assumptions each interpretation makes about users, technology and content. Neither interpretation has yet become irreversible. 


\section{The Netcom Residential Broadband Network}

In late 1993, the Netcom consortium was formed to build and operate a broadband network, on a trial basis, in a new housing development not far from a major Canadian city. (Netcom is a pseudonym. Other research teams [e.g. Hampton, 1999] have used different pseudonyms for the trial, and some research has been published using actual names and locations.) The consortium included telecommunications companies, computer companies, systems integrators, health care providers, government agencies, libraries, real estate developers, multimedia content developers, colleges and universities. The consortium members agreed that the trial would be user-centred, have a strong research focus, and be pre-competitive and non-proprietary (i.e. in the trial environment competitors would work side by side and share research results). Membership was open to any interested organisation or individual who paid the membership dues. The trial plan outlined the objectives:

Netcom is a consortium of public and private organizations who share the goal of shortening the implementation time for full service broadband networks in [Canada]. Netcom is testing the city of tomorrow today. It's a broad bandwidth network complete with user access appliances, multimedia content and servers and information gathering that will result in a blueprint for living and working in a connected community. (Netcom, 1994)

Planning for the trial was under way by early 1994, but delays in constructing the homes meant that the first users were not connected until December 1996. Although the network could have served many more users, usage peaked at about 200 users (in approximately 70 homes) in 1998.

A symmetrical HFC (hybrid fibre coax) network provided broadband connectivity at speeds up to $10 \mathrm{Mbps}$. Services available free of charge on this broadband network included videophones, CD-ROM-based content on demand (e.g. children's games, entertainment, educational materials), music on demand (a jukebox-like service where users could create their own play lists), high speed internet access, e-mail and a community listserv. Collectively, these services were referred to as network 'content'. This content was accessed through specially configured high performance home computers, purchased by users from the Netcom consortium at a reduced price. Users 
could connect to the network from multiple access ports in their homes (although only one computer per house could access the Netcom network at a time).

In early 1998, the consortium had announced that within the next year it would be able to offer services to upward of 3000 users, by extending the network into the local community (Netcom, 1998). As 1998 went on however, circumstances changed and a key player in the consortium announced that it intended to withdraw at the end of that year. An effort was made to keep the consortium going without this partner, but by this point residential broadband services were becoming available in some markets on a commercial basis, so the value of the Netcom trial as a research site was diminishing. The cost of continuing would have been high, so the decision was made to end the trial in December 1998.

This decision created an uproar among the users, who believed that they were part of a five year trial of broadband services, not a two year trial. What was most upsetting to many users was that there was no option to continue to receive service by paying for it. The consortium had decided to decommission the network completely, rather than operate it on a fee for service basis, leaving users with the choice of internet access by cable modem or by dial up modem (the area was not served by DSL at the time). The consortium did provide free dial up modem service for some months after the trial ended, and arranged for the community listserv to be transferred to a new owner. All other services were discontinued, and the HFC networking equipment was removed from the community in early 1999.

Several research initiatives were associated with this trial, and data were gathered in a variety of forms for different purposes. The results and analysis presented here draw from multiple sources, including trial documentation, focus groups conducted with users in July 1997 and June 1998, field notes from visits to the trial site and attendance at trial meetings, archives of the Netcom community listserv, and a series of 34 in-depth interviews with infrastructure providers, content developers and others involved in establishing and operating the trial. 


\section{Story 1}

Although it was noted earlier that the trial's objective was to offer a wide variety of services to users, many members of the Netcom consortium expressed disappointment that they had been unable to provide truly valuable services to users or to fully exploit the potential capacity of the broadband network. This is the central theme that is explored in story 1 . The representative quotations provided here summarise the key sentiments consortium members expressed when interviewed about the outcomes of the trial.

The real estate developer notes the inability of the consortium to deliver content and services that were valuable to the users.

If we had services that were truly valuable to the customer I think it would have been a different -- a very different story. The problem that we always had and still have until the last day of the trial is that consumers -- we could never really describe to consumers what it is that all of this really meant to them and how does this really make your life better?

These sentiments are shared by other consortium members, as the following comments show.

We had a responsibility to make sure that the content was compelling, that it was constantly being refreshed, that there was always something new, because the interest was there. We just -- I think we let them down, on our end, as a consortium, yeah, I really think so. It's unfortunate.

Content is what consumers want to see. They want to see a value proposition. And access alone is not a value proposition. Or it's a value proposition that can't be sustained. After a while, consumers want more than just access. ... So what I'm saying is access alone is not a sustainable value proposition. Sooner or later you gotta put compelling content and applications in front of consumers to retain them, to get their loyalty, and they never, they never did that.

...the Netcom trial, or ADSL, or the cable modems, I mean this is the platform to the home of the future. And, you know, everything, all the future services will be riding on that platform, and that technology. And it's a battle, it's a battle for the family room. I don't really mean just the family room, but it's a battle for the family room with respect to who's going to be the company that's going to be delivering those new services to the new consumer.

There was no doubt that Netcom's technical platform was excellent, "a fantastic hardware platform to work on". In another consortium member's words, "It was really good. It was a great service, for the customers. It was reliable ... the way we provisioned it was very customer friendly. There was a lot of bandwidth available to a 
limited number of customers. And we didn't have too many problems, at all, really." But the network's technical excellence led to more frustration on the part of consortium members as they were not able to obtain content that fully exploited the HFC broadband network's potential capabilities.

We tried hard to increase the video content, but again, we couldn't get anyone to, even though we had carefully built the infrastructure that would support a lot of video, including links with [a partner] with their massive storage, and getting hooked up onto the internet backbone so we could actually move data files around etc. And we really wanted to explore what everyone talked about, which was quote unquote convergence. The union of TV and PC, which we really did have the ability to do.

A housing sales person explains part of the sales pitch as "talking about the technology and the opportunity, tomorrow's technology today", but then remarks, "we never had, the reality of what we had to offer was never quite as good as the story. And I'm not sure that the reality that existed in the purchasers' homes was ever as good as the story".

The trial was characterised as a series of missed opportunities:

There was a lot more that we wanted to do. I think there were a lot more things that we could have done that would have been fascinating, that would have been extraordinary results for our members. Home automation, new applications development, streamed video. I think there was a lot more we could have done there, that would have been of extraordinary benefit. Shopping applications, e-commerce applications, we never got into any of that.

In summary, this story is one of unrealised potential. Consortium members recognised the technical value of the HFC network, and were frustrated that it was not used to the full extent possible, in terms of delivering services like video that could only be made available on a high bandwidth network. This story suggests that there is value in broadband, but to fully realise that value the broadband network must be used to deliver engaging content and services to users. A killer app is needed to drive demand for broadband. Despite consortium members' best efforts, there was no killer app. There was not enough content available at Netcom to demonstrate the value of broadband connectivity, or to find out which services really were preferred. There was a strong sense of failure in terms of delivering content, but also an underlying belief that 
had the problems in getting content been overcome, the outcomes would have been quite different.

\section{Story 2}

This story is told in the same manner as the first, by drawing together representative quotations. In this story though, users have centre stage, and their comments are as important here as those from consortium members. This is a story of community and connectivity, not of technology and content. A good starting point for this story is the following message that was posted by a user to the community listserv, after it was announced that the trial would be ending.

I'm a home owner [here] and l've been weeding through all of the chafe [sic]on
the mailing list with regards to the end of the Netcom Trial. This has led to a
discussion at my office and an idea that could benefit my company and my
neighborhood. We are in the process of packaging a product specifically for
online communities. It just so happens I live in one. Well for the time being
anyhow. Besides the free Internet access we're enjoying, I think what the
residents here have become most attached to, is the online community. This is
why they are irate at the loss of their wired community, to them it's like ripping
apart the neighborhood. I am emersed [sic] in email all day long and should be
sick to death of it, but I'm going to miss it too. I think this is something that is
not easily measured by the people studying the trial, one because there's no
previous data on it, but mostly because it's an emotional attachment. Other users expressed similar thoughts on the listserv about the strong attachment they felt to their community. One wrote, "I have walked around the neighbourhood a lot lately and I have noticed a few things. I have noticed neighbours talking to each other like they have been friends for a long time. I have noticed a closeness that you don't see in many communities." Another person wrote,

My family enjoyed being on the trial. We had acess [sic] to free internet, free health nurse and free games for the kids. We got a good deal on a computer, which we would not own now if it were not for Netcom and we now own a free telephone. We did not buy our house because it was a smart home, but look at the computer system as a bonus that came with our house. We live in a great community, have the chance to talk to all of you through a community e-mail, and have contributed to a worthwhile study.

A consortium member's comments on the winding down of the trial reiterate the strong sense of community that it engendered.

I must say that they [the users] don't need us anymore. What they're doing is email for the most part, and they can continue to do that. We haven't been giving them any good content for the last year and a half, that's been anything 
that's new and radical. Yes, their internet access will be slower for a while. But once they get onto [an ISP] or wherever they're going to go, even if they're on dial up, they can create a community mailing list exactly as they have now, and they just plain don't need us.

This attachment to community was widely recognised by the consortium members. To some it was a surprise, to others it was consistent with the trial's usercentred approach.

I actually think we succeeded in community and that wasn't part of what we had planned. At least it wasn't something that I had really thought about. And so, for me, just to realize that the basic connectivity, just being connected and having an easy way to reach one another was really important. I'm surprised at what goes on in those e-mails. It is everyday, mundane stuff but it's really important, compared to some of the other stuff. We say 'well we're going to concentrate on this, all they want is games, well no, they want garbage pickup.'

I'd personally like to have experienced it myself, actually live in a community where I could get these services. ... I've seen a community grow, and stand together which I never thought would have happened. Just the e-mail itself has united the community and made it stronger. They invited us to a community party once. I did not expect the turn out, all the people who were using our software were all friends and that was very incredible.

But again, one of the things that struck me was the way the whole package worked, which was part of the theory behind Netcom at the outset, that it was the whole shopping basket of human activity that would generate the dynamic interest, and not a single specific application that we generated. The way, the presence of the network, and the existence of the trial, acted as a community catalyst, to me was one of most extraordinary, fundamental results of the trial.

Many consortium members were delighted that the community aspect of the trial had become so strong, and didn't hide the fact that this didn't require the broadband network the trial had built. In the words of the trial director, "the listserv had become the number one application of community use, and what was of interest to us of course was that it was a low band application and did not require the expensive network that we built". One consortium member observed that "the low tech side of it, the community side of it, was really vibrant", while another noted "the high speed thing was all just window dressing. The meat and potatoes of connectivity is sufficient to produce something interesting".

Other observations supplement this story line, showing that users wanted to have control over how they used the network, rather than being on the receiving end of someone else's content. A consortium member developing health care services makes this point. 
I made a mistake, in the sense of assuming that people wanted a lot of information and what they wanted to do was talk to each other. So when you take a broader view of health, you know, from a health promotion clinic standpoint, the real beauty of it came from self-help, came from finding babysitters, you know, organizing around the teachers' strike. It was bottom up stuff. I mean, we know this. ... not this barrage of information and music and this and that. And how arrogant, and I'm including myself in this -- that's why I can say it -- to think that you know, you know what people need and want and how they are going to use it.

The music on demand service enabled user control of content, as one of the trial's programmers explains here.

To tell you honestly, I really enjoyed the music part. It wasn't too long ago we got it going but I really enjoyed the music part because I could put it in the background and listen to it. And the best part about it is that I can create my own play list. I don't have to listen to a whole album, I can just pick out the things that I like, it's like creating your own tape.

Another interesting part of this story is that the Netcom network was designed as a symmetrical one, meaning that users had almost the same bandwidth going out of their homes as into them. A consortium member explains the significance of this network design.

And in fact that is not the way the industry is going, they're going with something that is quite asymmetric, which is people want way more in than they want to put out. I think [the decision to make the Netcom network symmetric] was perhaps a decision that happened years and years ago. ... That was a very critical thing because you go and say "hey listen, on this network you are a peer to the broadcaster, you are a peer to other things, you, the homeowner, could be providing things at high speed as well", which actually led to some very interesting stuff you know. Some of the people that wanted to join the community were ones who wanted to become internet service providers. So I will provide a service based out of the community, because I know it will have infrastructure to do that.

In summary, this is a story of community and connectivity. Users valued their connections to each other. They were not particularly interested in content developed by others, they were more interested in the content they were creating themselves through the development of their own on- and off-line community of neighbours. In this story, the technology had no residual value, it was of use because it provided a conduit between community members, all of whom could send and receive messages and other content as equals on the network. There was no need to wait for someone to develop a killer app, users found their most popular activities involved e-mail and connecting with their peers. 


\section{Discussion}

The key to understanding the differences between these two stories lies in the assumptions made in each about content. A dictionary definition of content as "what is contained in something" is helpful here. In both stories above, the broadband network contains something, the difference is in what is contained, who provides it and what value is ascribed to it. The differences between the two stories can also been seen when describing broadband networks as socio-technical systems (Bostrom \& Heinen, 1977). The technical part of Netcom's residential broadband network is easy to identify, it is the hybrid fibre coax network built by Netcom. Netcom's social component is the users. But it is less clear where content fits in. In story 1, the success of the technology is linked to the existence of content. Without content, which story 1 defines as something (e.g. applications and services) that is delivered to users over the technical network, the technical network is not successful. But in story 2 , users are not dependent upon the network to deliver content, instead they generate their own content by using the network as a tool for communication and connectivity. Content is a part of the social component in Story 2.

Figure 1 offers a graphic representation of the actor-networks related to each story, and shows how different meaning accrues to the network and content in each instance. The left side of the diagram shows that in story 1 , content is an integral part of the technical system. According to this story, once better content is available, it can be broadcast to users and will demonstrate the value of broadband networks. Content is viewed as a means to realise network potential. In contrast, the right side of the diagram illustrates story 2 , where content originates with the users. In this interpretation, content is part of the social component of the socio-technical network. The broadband network is valuable to users because it allows them to connect with each other and share the content they have generated. 


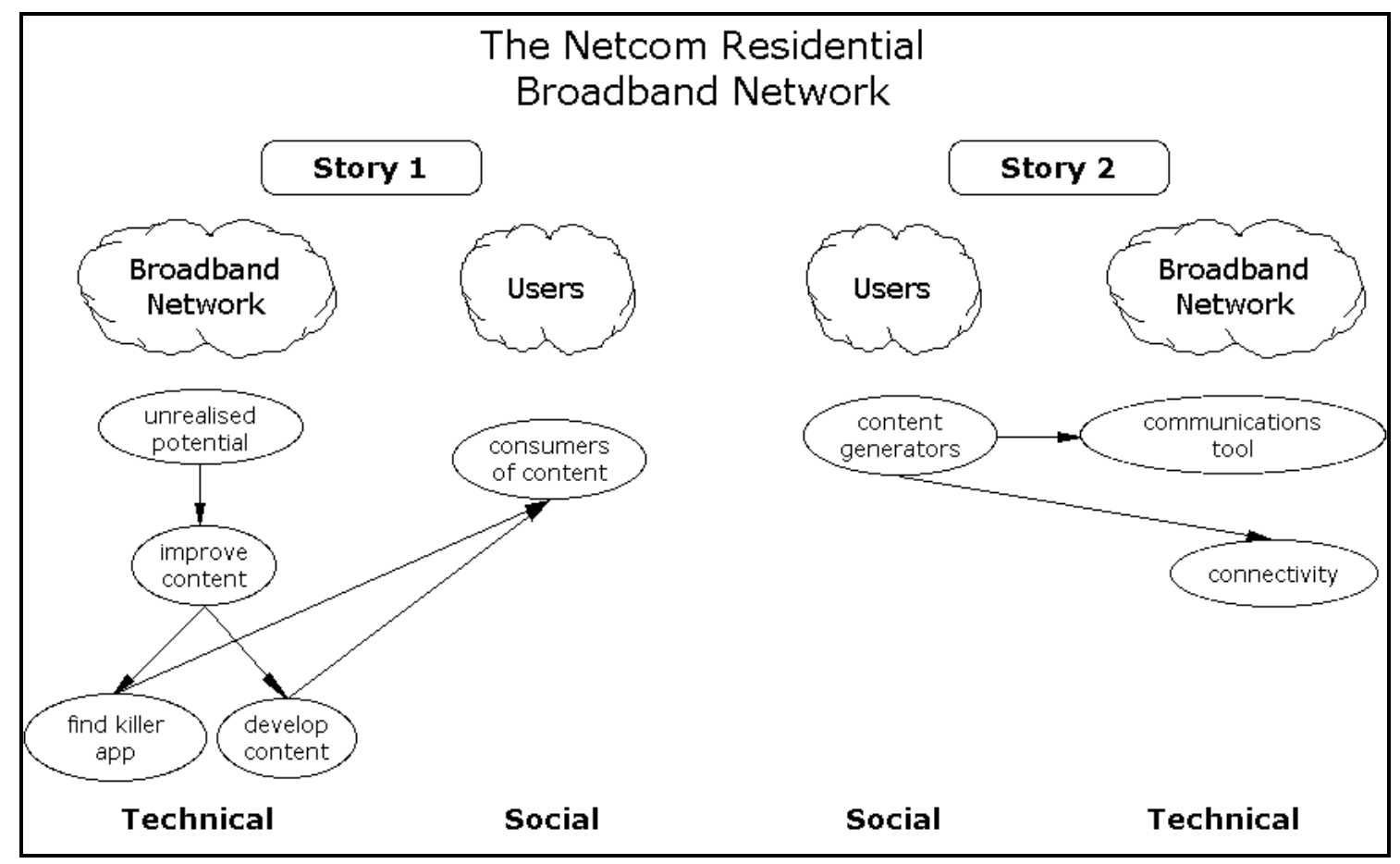

Figure 1: Graphical Comparison of the Netcom Stories 
The differences between the two stories are summarised in Table 1. Shading is used to show the positioning of content. As diagrammed above, in story 1 content is tightly linked to the technology, whereas in story 2 it is linked to the users.

\begin{tabular}{|c|c|c|c|}
\hline & Technology & Content & Users \\
\hline $\begin{array}{l}- \\
\frac{7}{0} \\
\dot{\omega}\end{array}$ & $\begin{array}{l}\text { valued for technical } \\
\text { capabilities, but content } \\
\text { essential to provide } \\
\text { value to users } \\
\text { - capacity to transfer data } \\
\text { at rapid rates to users }\end{array}$ & $\begin{array}{l}\text { - tightly linked to } \\
\text { technology } \\
\text { - content makes the } \\
\text { technology valuable } \\
\text { - 'appropriate' content } \\
\text { uses full capacity of } \\
\text { technology } \\
\text { - few content providers, } \\
\text { content often controlled } \\
\text { by owners of technology }\end{array}$ & $\begin{array}{l}\text { - consumers of } \\
\text { technology-content } \\
\text { package } \\
\text { - revenue source for } \\
\text { technology providers as } \\
\text { consumers of content } \\
\text { - recipients of content, not } \\
\text { contributors }\end{array}$ \\
\hline 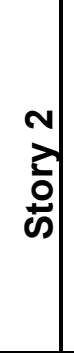 & $\begin{array}{l}\text { valuable as a means of } \\
\text { connecting users, } \\
\text { technology is a pipe } \\
\text { must support data } \\
\text { transfer between users, } \\
\text { with users having full } \\
\text { capacity to send and } \\
\text { receive data }\end{array}$ & $\begin{array}{l}\cdot \text { generated by users } \\
\bullet \\
\text { conany content providers } \\
\text { cochnology }\end{array}$ & $\begin{array}{l}\text { content generators } \\
\text { full participants in } \\
\text { exchange of content }\end{array}$ \\
\hline
\end{tabular}

Table 1: Assumptions about Technology, Content and Users Embedded in Netcom Stories

\section{The Implications of Interpretive Flexibility and Irreversibility}

The analysis above indicates that at Netcom, the residential broadband network did not reach a state of irreversibility or closure. The data presented show that there was not a shared understanding of how the residential broadband network could be used or what it was about, instead the co-existence of the two stories demonstrates interpretive flexibility. Thus any analysis of the Netcom trial should acknowledge that although a killer app (believed to be needed to justify the usage of broadband connectivity) did not exist, this did not mean that the trial was a failure. The trial showed the value of empowering users as content generators, and providing them with connectivity. 
Because they had different perspectives on the trial, Netcom consortium members (the people and organisations who built the network and developed content and services) were not included in the actor-network diagram showing the two Netcom stories. As might be expected, the consortium members could be divided into three groups: those whose interpretation of the trial was most consistent with story 1 ; those whose interpretation was most consistent with story 2; and those who could identify and articulate both stories. Because the trial ended when it did, it is unclear whether the presence of two interpretations would have become problematic as the trial continued. This is an important question however, as commercial internet services providers are now offering broadband network connectivity to consumers, and the two interpretations of what the networks are about persist in the commercial deployments.

\section{Conclusions}

It is very easy to find evidence of the story 1 interpretation of residential broadband in commercial deployments. This is the dominant story, one that has been accepted in, and is continually reinforced by, the business press. For example, both Forbes ASAP and Fortune magazines quoted US-based consultant Ford Cavallari, who argued that "Applications are going to be the regulator and demand creator for broadband ... Broadband is never going to take off without them." (Zerega, 2000, p. 111.) "Customers are looking for the application that makes the broadband world touchable and believable to them, that underscores its benefit. And that application does not yet exist."

There is much evidence to suggest that network service providers (e.g. cablecos and telcos), broadband content developers and telecommunications equipment manufacturers believe that the story of residential broadband is that demand will be created and sustained by the delivery of the content they choose to provide over high bandwidth connections into consumers' homes (e.g. interactive television, videos on demand, and other entertainment services). It is this sort of reasoning that led to the 
Time Warner-AOL merger in the US. Given this mindset, it is easy to understand why some Netcom consortium members and others outside the trial were reluctant to accept research findings that indicated users didn't need to be provided with content, but rather that they preferred to develop and control it themselves.

The history of technology indicates that most technologies do achieve irreversibility (Latour, 1987; Callon, 1991). Over time, multiple interpretations of the technology disappear as a common understanding of what it is about emerges. The question that arises here is what the common understanding of residential broadband will be. Based on a reading of the dominant perspective, it suggests that residential broadband networks will be controlled by service providers who develop and deliver content to users. In order for this model to be successful, content-based killer applications must be found to drive demand for broadband access. But if the alternative view, which is contrary to the fundamental assumptions and values of those currently developing residential broadband services, is accorded validity, then it calls into question the underpinnings of the industry and the fundamental nature of many businesses involved in developing consumer-based broadband networks and services.

There is no crystal ball to show which perspective will be the one that persists for residential broadband in the long run. Indeed, there may be other perspectives and interpretations of residential broadband that have yet to emerge. What is known however, is that with other communications technologies, including the telephone, teletext and videotex, a user-based, story 2 perspective has shaped the way in which these technologies were adopted.

Fischer's $(1988 ; 1992)$ studies of how the telephone was adopted show that its initial usage was modelled after the telegraph. As such, it was intended for sending messages. It was also used as a broadcast device, transmitting music and news to telephone subscribers (Aronson, 1977; Briggs, 1977). Social uses (e.g. chatting with friends and family) were strongly discouraged. It wasn't until the 1920s that the telephone was promoted as a mechanism for 'sociability' (see Fischer, 1988 on this 
point), yet this is by far the most common usage for consumers today. Consumers do not use the telephone as a one way transmission mechanism (the story 1 perspective), instead they create their own content by interacting with friends, family and associates.

In Japan in the early 1970s, the Tama CCIS and Hi-Ovis experiments provided community information services to residents in their homes. Researchers found that a pay television service, expected to be popular among users, was not widely used. The most popular service was 'memo-copy', which provided local information to users (including sales at local shops, listings of services available on holidays and public announcements) in a one minute fax transmission (Masuda, 1981). The preference for local community-based services over broadcast entertainment content (pay television) is consistent with a story 2 perspective, in that the community-based services were providing connectivity among a group of users.

Similar innovation patterns have been observed in consumers' usage of videotex services. In France, the Minitel system quickly moved from a service that provided primarily person-to-machine interaction and communications (e.g. telephone directory listings) to one where person-to-person messaging was popular (Allen, 1988). In Canada, it was noted that "successful marketing of videotex will be contingent upon the development of interactive transactional services" (Wilson, 1984, p. 12). When the Canadian Telidon videotex system did not develop a market for transactional services it was generally considered a failure. But as Devon (1991) and Slofstra (1984) note, this assessment overlooked an active community of videotex users using the system as a means of communicating and sharing graphics among individuals.

Perhaps residential broadband networks are different from other communications technologies, and they will be successful in creating demand based on a 'content delivered to users/killer app' model, as outlined in story 1. But it is possible that residential broadband networks aren't different from earlier technologies, as described above, and that the 'user in control' model outlined in story 2 will prevail. This does not mean that there is no market for residential connectivity, but it does mean that its nature 
needs to be reconsidered. In this case, the implications of the question 'who needs a killer application' must be understood by anyone wishing to succeed as a provider of residential broadband connectivity. 


\section{References}

AKIMARU, H., FINLEY, M.R. and NIU, Z. (1997): Elements of the emerging broadband information highway. IEEE Communications Magazine 35(6):84-94.

ALLEN, D. (1988): New telecommunication services: Network externalities and critical mass. Telecommunications Policy(September):257-271.

ARONSON, S.H. (1977): Bell's electrical toy: What's the use? The sociology of early telephone usage. In The social impact of the telephone. 15-39. de Sola POOL, I. (ed) Cambridge, MA, MIT Press.

BARTSCH, F.-R. and AUER, E. (1997): Lessons learned from multimedia field trials in Germany. IEEE Communications Magazine 35(10):40-45.

BIJKER, W.E., HUGHES, T.P. and PINCH, T.J. (eds) (1987): The social construction of technological systems. Cambridge, MA, MIT Press.

BOLAND, R.J. and SCHULTZE, U. (1996): From work to activity: Technology and the narrative of progress. In Information technology and changes in organizational work. ORLIKOWSKI, W.J., WALSHAM, G., JONES, M.R. and DeGross, J.I. (eds). London, Chapman \& Hall.

BOSTROM, R.P. and HEINEN, J.S. (1977): MIS problems and failures: A socio-technical perspective, part 1 - The causes. Management Information Systems Quarterly 1(3):17-32.

BRAGITIKOS, M. (1996): Just what will take the net from a novelty to a necessity? Wall Street Journal Interactive Edition. New York.

BRIGGS, A. (1977): The pleasure telephone: A chapter in the prehistory of the media. In The social impact of the telephone. 40-65. de Sola POOL, I. (ed) Cambridge, MA, MIT Press.

BRODEUR, R. and AGARWAL, K. (1996): Bell Canada trials provide high bandwidth for interactive, multimedia, and internet services. Telesis. (102):41-42.

CALÁS, M.B. and SMIRCICH, L. (1999): Past postmodernism? Reflections and tentative directions. Academy of Management Review 24(4):649-671.

CALLON, M. (1991): Techno-economic networks and irreversibility. In A sociology of monsters: Essays on power, technology and domination. 132-161. LAW, J. (ed) London, Routledge.

DEVON, T. (1991): Interactivity and the popular support for Telidon. Canadian Journal of Communication 16(2):307-311.

DI CONCETTO, M., PAVARANI, G., ROSA, C. and ROSSI, F. (1999): AMUSE: Advanced broadband services trials for residential users. IEEE Network 13(2):37-45.

DIRECTORATE FOR SCIENCE TECHNOLOGY AND INDUSTRY (2001): The development of broadband access in OECD countries. OECD.

DIXIT, S. (1999): Data rides high on high-speed remote access. IEEE Communications Magazine 37(1):130-141.

FALKUS, D. (1997): How attractive is interactive? Communications International 24(6):39-42.

FISCHER, C. (1988): Touch someone: The telephone industry discovers sociability. Technology and Culture 29:32-61. 
FISCHER, C.S. (1992): America calling: A social history of the telephone to 1940. Berkeley, University of California Press.

HAMPTON, K.N. (1999): Netville online and offline: Observing and surveying a wired suburb. American Behavioral Scientist 43(3):475-492.

HERNANDEZ-VALENCIA, E.J. (1997): Architectures for broadband residential IP services over CATV networks. IEEE Network 11(1):36-43.

HUMPHREY, M. and FREEMAN, J. (1997): How xDSL supports broadband services to the home. IEEE Network 11(1):14-23.

IMS, L.A., MYHRE, D. and OLSEN, B.T. (1997): Economics of residential broadband access network technologies and strategies. IEEE Network 11(1):51-58.

INTERNATIONAL TELECOMMUNICATION UNION (1997): Vocabulary of terms for broadband aspects of ISDN.

KHASNABISH, B. (1997): Broadband to the home (BTTH): Architectures, access methods, and the appetite for it. IEEE Network 11(1):58-69.

LATOUR, B. (1987): Science in action. Cambridge, MA, Harvard University Press.

LATOUR, B. (1999): On recalling ANT. In Actor network theory and after. 15-25. LAW, J. and HASSARD, J. (eds). Oxford, Blackwell.

LAW, J. (ed) (1991): A sociology of monsters: Essays on power, technology and domination. London, Routledge.

LEA, M., O'SHEA, T. and FUNG, P. (1995): Constructing the networked organization: Content and context in the development of electronic communications. Organization Science 6(4):462-478.

MADDOX, K. (1994): Setbacks on the superhighway. Advertising Age. 65(12):IM2.

MASON, C. (1997): High hopes drowned in dollars. America's Network.16.

MASUDA, Y. (1981): The information society. Washington, DC, World Future Society.

MIDDLETON, C.A. (1999): Residential broadband networks: Preliminary findings from a Canadian 'information highway' trial. Proc. WITS '99, Charlotte, NC, 161-166.

MONTEIRO, E. and HANSETH, O. (1996): Social shaping of information infrastructure: On being specific about the technology. In Information technology and changes in organizational work. ORLIKOWSKI, W.J., WALSHAM, G., JONES, M.R. and DeGross, J.I. (eds). London, Chapman \& Hall.

MOORE, S. (1994): The killer app crew. Computerworld.145-146.

NATIONAL BROADBAND TASK FORCE (2001): The new national dream: Networking the nation for broadband access. Ottawa, Industry Canada.

NATIONAL RESEARCH COUNCIL (2002): Broadband: Bringing home the bits. Washington, DC, National Academy Press.

NETCOM (1994): Trial plan.

NETCOM (1998): Minutes of the annual general meeting.

RATH, K., WANIGASEKARA-MOHOTTI, D., WENDORF, R.G. and VERMA, D.C. (1997): Interactive digital video networks: Lessons from a commercial deployment. IEEE Communications Magazine 35(6):70-74.

SHELANSKI, H.A. (1999): The speed gap: Broadband infrastructure and electronic commerce. (The legal and policy framework for global electronic commerce). Berkeley Technology Law Journal 14(2):721. 
SLOFSTRA, M. (1984): User group speaker tries to dispel myths about Telidon. Computing Canada. 10(11):14.

SNODDY, R. (1995): Internet finally earns stamp of approval in US. Marketing London.5.

SOMERVILLE, I. (1997): Actor-network theory: A useful paradigm for the analysis of the UK cable/on-line sociotechnical ensemble. Proc. AIS - Americas Conference on Information Systems, Indianapolis, 110-112, GUPTA, J.N.D. (ed) Association for Information Systems.

TATNALL, A. and GILDING, A. (1999): Actor-network theory and information systems research. Proc. Australasian Conference on Information Systems, Wellington, NZ, 955-966.

VIGDEN, R. and McMaster, T. (1996): Black boxes, non-human stakeholders and the translation of IT through mediation. In Information technology and changes in organizational work. 250-271. ORLIKOWSKI, W.J., WALSHAM, G. and JONES, M. (eds). London, Chapman \& Hall.

WALSHAM, G. (1997): Actor-network theory and IS research: Current status and future prospects. In Information systems and qualitative research. 466-480. LEE, A.S., LIEBENAU, J. and DeGross, J.I. (eds). London, Chapman \& Hall/IFIP.

WASHBURN, B. and PERRIN, S.S. (1996): Residential broadband. Telecommunications 30(6):S33-S36.

WILSON, K. (1984): The wired home: An assessment of market and ownership trends in the videotex industry and their import for public policy. McGill University Graduate Program in Communications.

WOOLGAR, S. (1991): Configuring the user: The case of usability trials. In A sociology of monsters: Essays on power, technology and domination. 58-99. LAW, J. (ed) London, Routledge.

ZAHARIADIS, T., ROSA, C., PELLEGRINATO, M., LUND, A.B. and STASSINOPOULOS, G. (1997): Interactive multimedia services to residential users. IEEE Communications Magazine 35(6):61-68.

ZEREGA, B. (2000): Highway to nowhere. Forbes ASAP.111-112. 


\section{Copyright}

Please note ACIS copyright that was originally applied to this paper.

(C) The author assigns to ACIS and educational and non-profit institutions a nonexclusive licence to use this document for personal use and in courses of instruction provided that the article is used in full and this copyright statement is reproduced. The author also grants a non-exclusive licence to ACIS to publish this document in full in the Conference Papers and Proceedings. Those documents may be published on the World Wide Web, CD-ROM, in printed form, and on mirror sites on the World Wide Web. Any other usage is prohibited without the express permission of the author. 
Biographical Note:

Catherine Middleton recently earned her Ph.D. from the Schulich School of Business at York University, in Toronto, Canada. This paper draws from her dissertation research, which investigated residential usage of broadband technologies (including high speed internet access and multimedia services). Dr. Middleton is a faculty member at Ryerson University's School of Information Technology Management, where she teaches courses in eBusiness, strategic uses of IT, and diffusion of communications innovations, and continues her research in the area of consumer usage of broadband technologies. 